\title{
Regulação às avessas? Uma análise sobre a legislação urbanística instituída nos municípios da Região Metropolitana de Campinas entre 1970 e 2006
}

\author{
Regulation inside out? An analysis about the urban \\ regulation instituted in the municipalities of the Campinas \\ Metropolitan Region between 1970 and 2006
}

Sidney Piochi Bernardini

\section{Resumo}

Este artigo pretende discutir o universo dos mecanismos normativos de regulação urbanística implementados em 19 municípios da Região Metropolitana de Campinas entre 1970 e 2006. Duas questões aqui serão discutidas: os limites da autonomia municipal na gestão do uso e ocupação do solo e das suas normas como indutoras de um desenvolvimento urbano benéfico a toda a sociedade. Os substratos, condicionantes e forças (inclusive legais) que impulsionaram as transformações no âmbito do processo ainda constituem uma lacuna no vasto campo de investigações sobre o modelo de urbanização da Região Metropolitana de Campinas. Os resultados alcançados demonstraram que esses municípios instituíram 3.087 instrumentos de regulação urbanística no período, sendo $85 \%$ deles promulgados para promover modificações pontuais nestes.

Palavras-chave: regulação urbanística; uso e ocupação do solo; zoneamento; urbanização; Região Metropolitana de Campinas.

\begin{abstract}
This article intends to discuss the universe of urban regulation normative tools implemented in 19 municipalities of the Campinas Metropolitan Region between 1970 and 2006. Two issues will be discussed here: the limits of municipal autonomy in the management of land use and occupation and the limits of its norms in promoting an urban development that benefits the society as a whole. The substrata, conditionings and forces (legal forces included) that have boosted transformations in the scope of the process still constitute a gap in the large field of investigations about the urbanization model of the Campinas Metropolitan Region. The results showed that these municipalities instituted 3,057 urban regulation tools in the period, and $85 \%$ of them were promulgated to promote specific modifications in the municipalities.
\end{abstract}

Keywords: urban regulation; land use and occupation; zoning; urbanization; Campinas Metropolitan Region. 


\section{Introdução}

Este artigo tem como objetivos principais apresentar e discutir, no âmbito da Região Metropolitana de Campinas, como ocorreram a institucionalização e a gestão do uso e ocupação do solo sob a perspectiva do planejamento e ordenamento físico-territorial de seus municípios constituintes, a partir da análise dos mecanismos legais estabelecidos entre os anos de 1970 e 2006 . A constatação de tais características por pesquisas já realizadas, como as de Mitica Neto (2008) e Pires (2007), apontam para uma prática comum de produção do espaço urbanizado na maior parte dos municípios dessa Região, indicando, em hipótese, que existe uma certa sinergia (como também indicou Pires) entre os interesses privados do mercado incorporador e iniciativas e procedimentos conduzidos pelos poderes públicos locais. Essa sinergia não só explica a conduta comum definida pelos municípios como também pode demonstrar em que bases ela se opera. Pretende-se, com isso, demonstrar que o encadeamento exacerbado de instrumentos legais urbanísticos de todas as ordens postulados pelos Poderes Executivos e aprovados pelos Poderes Legislativos criou um arsenal volumoso de medidas intimamente acopladas aos interesses particulares. Nesse ponto de vista, pretende-se discutir a validade dos ritos instituídos e apontar possíveis impactos e consequências das arbitrariedades observadas.

Alguns estudos, como o de Harris (2015), que se debruça sobre o interesse público nos processos de desapropriação compulsória de terras privadas nos Estados Unidos, demonstra que, já nos anos 1960, houve uma transição nas formas de conduzir esses processos vinculados a uma coalisão entre governos, incorporadores, empreendedores privados e outros agentes imobiliários nas ações de renovação urbana, remoção de favelas e expansão das áreas centrais como estratégias para a "revitalização das cidades", sob a égide dos poderes locais. Assim também, por outro lado, nos processos de "barganha lote a lote", nas decisões sobre as regras de zoneamento das cidades estadunidenses, nas quais a voz dos moradores locais, em processos democraticamente legítimos, prejudica a intensificação do uso do solo e os adensamentos populacionais sob o discurso do Not In My Back Yard (NIMBY), ocorre uma sobrevalorização dos imóveis urbanos que, segundo Hills Jr. e Schleicher (2015), intensifica a crise da moradia e o empoderamento da indústria da incorporação de terras. Aqui o debate sobre a relação entre o planejamento compreensivo, como matriz do pensamento sobre o desenvolvimento urbano, e as restritivas regras de zoneamento, nem sempre vinculadas a esse pensamento, ganha contornos mais complexos.

A permanência do plano diretor como principal instrumento da política de ordenamento municipal perpetua a sua figura como meio ideológico para o setor imobiliário e o poder público justificarem suas atuações em defesa do desenvolvimento urbano. Nesse ponto, a distância que se estabelece entre a retórica contundente desses planos e os efetivos instrumentos de regulação e controle de uso do solo consolida e mascara os mecanismos já consagrados da produção imobiliária (Villaça, 2012). No âmbito da gestão do uso e ocupação do solo, concepção, instituição e aplicação das leis urbanísticas são partes intrínsecas do 
cotidiano dos gestores públicos municipais que, sob o manto de uma profunda legalidade estruturada, operam leis que não possuem sanções para quem as infringem; que são impossíveis de serem cumpridas; que eles não têm capacidade de aplicar ou fiscalizar e até mesmo que se limitam a princípios gerais e generalidades que não afetam, em nenhum grau, qualquer ação de intervenção ou controle sobre o território (ibid.).

Essa dimensão da fronteira legal - ilegal, nas imperfeições subliminares da esfera burocrática, adapta-se muito bem aos ritos instituídos e conduzidos para possibilitar ao mercado formal o aval às suas atividades de incorporação. A malha excessiva, complexa e inchada de leis, decretos e mecanismos que corroboram esses ritos, longe de ser abarcada e compreendida pela sociedade e até mesmo pelos que a opera, define esse cotidiano da gestão urbana, sem haver, muitas vezes, qualquer questionamento por ela e por outros poderes constituídos. Assim é que, mesmo apontada pela literatura como uma das dimensões da estreita fronteira entre legalidade e ilegalidade, a forma como esses institutos legais são aplicados e os caminhos pelos quais se dão as restrições e permissividades nas escolhas efetivadas pelos poderes locais ainda merecem ser aprofundados nas investigações sobre gestão urbana no Brasil, sob as mais variadas óticas. Supõe-se que, nessa esfera de decisões, as práticas referenciem-se na inversão da ilegalidade pela legalidade (tornar legal o que seria ilegal), em ritos e práticas que consubstanciem os atos discricionários por mecanismos legais em uma associação estreita entre os poderes executivo e legislativo na produção dos seus instrumentos de poder.

\section{A Região Metropolitana de Campinas e os aspectos da sua configuração espacial}

A Região Metropolitana de Campinas, criada por força da Lei Estadual Complementar 870, de 19/6/2000, agrega 20 municípios. Vinculados a uma lógica comum que se consolidou com essa instituição, esses municípios conformaram uma rede urbana específica, determinada também por obras e intervenções realizadas por outras esferas governamentais, como a implantação da Rodovia D. Pedro I, por exemplo, e investimentos dos setores privados, com a instalação de novos parques industriais a partir, principalmente, da década de 1970. Com essas transformações significativas, no processo de interiorização da indústria no estado de São Paulo, o município de Campinas teve um papel preponderante sobre a sua região de influência, provocando atração de população e investimentos. Essa polarização induziu um movimento de transposição dos limites administrativos da cidade-sede, atingindo as cidades do entorno, estabelecendo-se relações específicas da rede urbana em formação (Cano e Semeghini apud Pires, 2007, p. 14).

A literatura destaca que, além de Campinas, outros municípios, como Paulínia, Valinhos, Sumaré e Indaiatuba, tiveram um crescimento industrial mais intenso na década de 1970, coincidindo com o processo de interiorização do desenvolvimento econômico do estado de São Paulo, desdobrando-se na modernização das atividades agropecuárias articuladas a indústria e serviços e no aumento das taxas de crescimento populacional (Pires, 2007, p. 14). Essas mudanças coincidiram com 
as determinações lançadas pelo governo federal, no âmbito do SERFHAU, da instituição de aparelhos planificadores nos municípios, condicionados a elaborarem seus planos diretores de desenvolvimento integrado em resposta às expectativas de investimentos que se pretendiam realizar nas várias localidades brasileiras. No outro extremo temporal coberto por este artigo (2006) está o prazo estabelecido, pela lei federal 10.257/2001 (Estatuto da Cidade) para que novos planos diretores fossem aprovados, o que poderia denotar uma mudança de postura e de rumos na condução da gestão municipal no tocante a aprovação e aplicação de instrumentos legais de caráter urbanístico.

Figura 1 - Mapa da Região Metropolitana de Campinas contendo as manchas urbanas de 1989 e de 2000

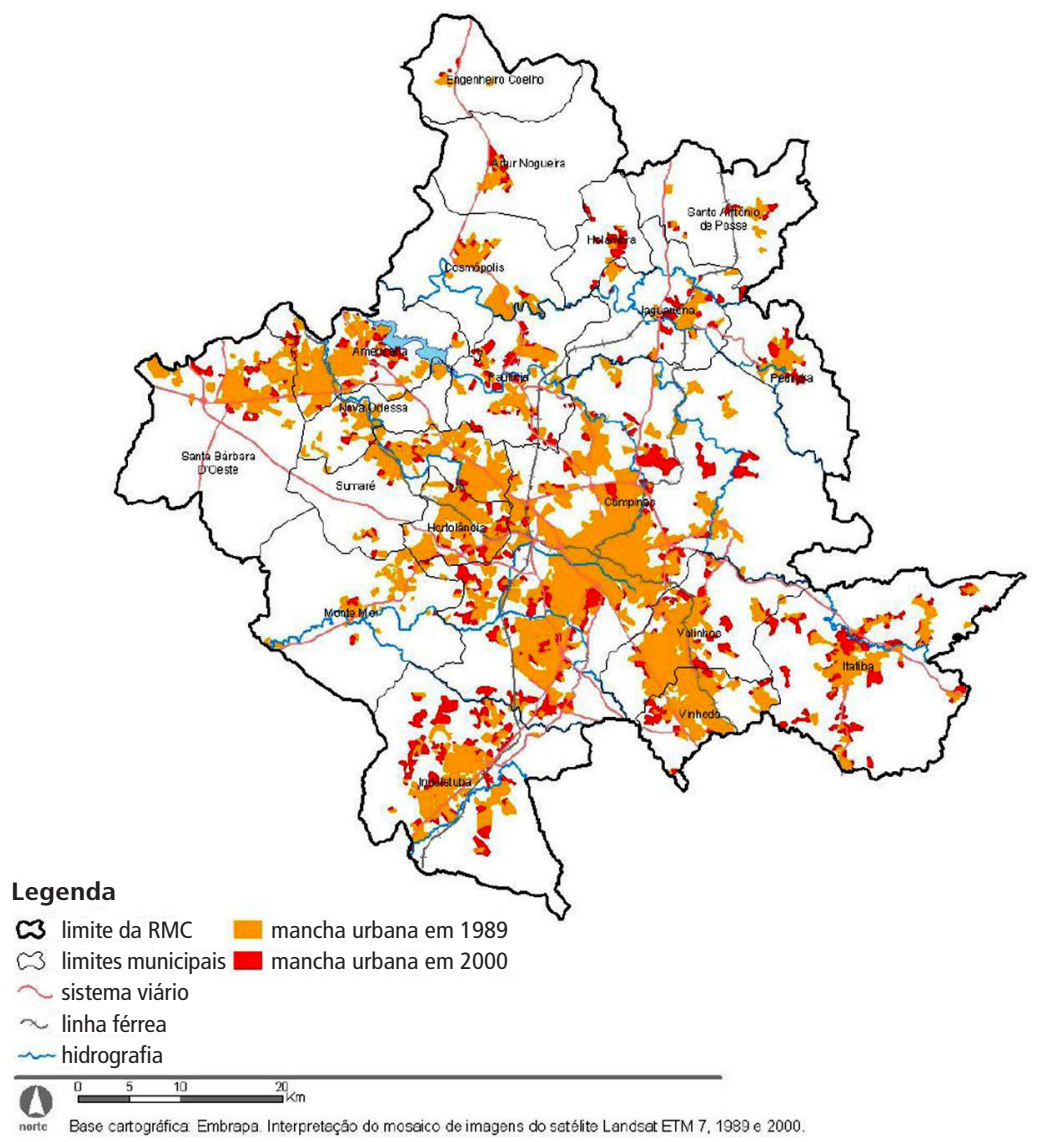

Fonte: Campinas (município). Plano Diretor de 2006 - Secretaria de Planejamento da Prefeitura Municipal de Campinas. Disponível em: http://www.campinas.sp.gov.br/governo/seplama/plano-diretor-2006/doc/tr_rmc.pdf 
É possível observar que, diferentemente de outras regiões metropolitanas criadas anteriormente, como o caso da Região Metropolitana de São Paulo, por exemplo, a espacialidade resultante da Região Metropolitana de Campinas não se caracterizou pela conurbação plena dos municípios integrantes, mas por fragmentação e dispersão territorial sintomática desse processo tardio e vinculado à Terceira Revolução Industrial, como aponta Soja (2000). Cabe alertar, nesse sentido, que a escala regional metropolitana escolhida se identifica com os pressupostos apontados por Villaça (1998) quanto à natureza dos espaços intraurbanos no Brasil, ao considerar que, nos processos de urbanização recentes, e no caso da Região Metropolitana de Campinas, em especial, a rede urbana ganhou um outro caráter, assim como também maior importância diante das pendularidades na dinâmica de deslocamentos diários da sua população, evidenciadas pelo Plano Integrado de Transportes Urbanos, de 2006, e à maior segregação a partir dos anos 1990, como demonstrou Cunha (2006).

Embora nos últimos anos tenha surgido um conjunto expressivo de estudos e pesquisas que se debruçaram sobre os aspectos essencialmente espaciais e morfológicos dessas novas configurações, não há muitos trabalhos, em São Paulo, que aprofundem as especificidades históricas da produção desses espaços sob a ótica dos mecanismos legais de planejamento e regulação urbanos instituídos e tomados em perspectiva regional e metropolitana. Vários artigos científicos, entretanto, apontam para tal preocupação em outros países do mundo, em especial nos Estados Unidos, como é o caso das pesquisas realizadas por Boarnet, McLaughlin e Carruthers (2011), que procuraram verificar o papel dos instrumentos de regulação urbana nas mudanças de padrões de densidade entre municípios urbanos e suburbanos na costa sudeste dos Estados Unidos; Bengston, Fletcher e Nelson (2004), que realizaram um balanço da bibliografia que trata dos instrumentos de regulação da expansão urbana nos Estados Unidos, enfatizando o papel preponderante dos agentes privados no processo de planejamento; Saizen, Mizuno e Kobayashi (2006) que observaram a falta de coordenação entre os diferentes sistemas de zoneamento (rural e urbano) na Região Metropolitana de Osaka, no Japão, investigando, com base nessa hipótese, as mudanças de uso do solo que ocorreram em três períodos, comparando-se essas mudanças com o status de zoneamento de cada período (bem aos moldes do que se pretende fazer nesta pesquisa); XI et al. (2012) que investigaram os potenciais impactos da implementação de estratégias para induzir o uso do solo rural nas fazendas rurais chinesas; Anthony (2004) que avaliou a eficácia das leis de controle da expansão urbana em 49 estados americanos, concluindo que os estados que manejaram 0 controle experimentaram menor declínio de densidade populacional do que aqueles que não o fizeram; Resnik (2010) que apresentou os limites dos métodos de planejamento baseados no chamado "Crescimento Inteligente" (Smart growth) para combater o espraiamento urbano nos Estados Unidos; Buzbee (2003) que, a partir das suas investigações, questiona o papel de estruturas e reformas legais como meios de induzir a expansão urbana de forma menos danosa à saúde pública.

Nota-se que o tema da expansão urbana "desordenada" e das novas formas de urbanização, pautadas principalmente pelos modelos 
de condomínios e loteamentos fechados, tem sido tratado sob as mais diferentes óticas por muitas pesquisas no Brasil e passaram a ser muito abundantes a partir da década de 2000, como pode ser notado pelo grande número de artigos publicados em Anais de Congresso e, especialmente, nos Anais da Enanpur de 2007, 2009 e 2011. No caso da Região Metropolitana de Campinas, não são poucos os trabalhos que discutem as bases de seus arranjos espaciais. A clássica publicação de Cano e Brandão (2002) apresenta um conjunto de artigos que perfaz um diagnóstico socioeconômico de cada um dos seus municípios. A publicação organizada por Fonseca, Davazo e Negreiros (2002) também se constitui numa obra de referência, mesmo passados mais de 15 anos de sua publicação, já que reúne artigos de vários estudiosos sobre questões relacionadas à gestão da Região Metropolitana. Sobre a ótica dos processos de vulnerabilidade e segregação em regiões brasileiras, a publicação organizada por Cunha (2006) apresenta alguns resultados da pesquisa desenvolvida junto ao Nepo (Núcleo de Estudos Populacionais) da Unicamp, incluindo a Região Metropolitana de Campinas. $\mathrm{Na}$ abrangência de outras pesquisas realizadas por esse Núcleo, muitas tratam da problemática relacionada aos processos de urbanização na Região, bem discutida por Baeninger e Gonçalves (2000) em uma excelente análise histórica e de sua dinâmica populacional.

É também considerável o número de teses e dissertações que foram desenvolvidas nos últimos anos. Dentre elas, destacam-se os trabalhos de: Pires (2007), sobre a relação entre expansão urbana e mercado imobiliário; Alves (2007) sobre a complexidade dos problemas metropolitanos sob a ótica da sua gestão, na mesma linha adotada por Jardim (2007), que, ao estudar cooperação e conflito nas relações intergovernamentais, estabeleceu bases de comparação entre os casos da Região Metropolitana e do Consórcio Intermunicipal do $A B C$ paulista; Costa (2012), que avaliou os impactos dos loteamentos fechados sobre os serviços ambientais a partir da apropriação da natureza pelos empreendimentos de alta renda, e Pereira (2008) sobre os processos de reestruturação urbana e os movimentos pendulares na Região. Os apontamentos apresentados por Caiado, que chegou a sistematizar e mapear os loteamentos fechados aprovados entre 1994 e 2004, podem também ser observados em vários artigos científicos (2006a, 2006b, 2007). Tomando como enfoque a questão específica dos loteamentos fechados, principalmente no município de Campinas, a tese de doutorado de Freitas (2008) merece ser destacada nesse campo de pesquisas. 0 município de Campinas destaca-se com algumas pesquisas referenciais, como as de Miranda (2002) que investigou as transformações do uso do solo rural para urbano no município; de Mitica Neto (2008), última parte da rede de trabalhos coordenados pelo professor Nestor Goulart Reis e uma das mais importantes pesquisas referenciais sobre as características do processo de urbanização, o papel do Estado e os arranjos espaciais resultantes. 0 município de Vinhedo, conhecido por ser um dos pioneiros a adotar o loteamento fechado e o condomínio horizontal como modelos de urbanização, está bem representado a partir da pesquisa de Pires (2004), que investigou as origens do processo de formação dos enclaves do município ainda na década de 1970. 
Ainda que os aspectos dos instrumentos de planificação e da legislação urbanística compareçam como base de estruturação das discussões travadas por essas pesquisas realizadas, eles não são o veio principal das investigações e não constituem as principais motivações que lhes deram origem. $A$ apresentação desse panorama em relação ao conjunto de estudos já desenvolvidos demonstra que um aprofundamento dos arranjos institucionais e de sua relação com as forças dos agentes de produção imobiliária, pela via dos instrumentos de planejamento e regulação, ainda é um desafio para incursões científicas que perseguem as explicações sobre os fenômenos associados à urbanização contemporânea.

Vale notar, ainda, que as diferentes abordagens recobrem questões e dilemas pertinentes às problemáticas contemporâneas, observando-se os efeitos imediatos dos processos como ocorrem. Centram-se na abordagem das mudanças configuracionais locais e regionais, nas recomposições territoriais a partir de suas dinâmicas populacionais, dos efeitos perversos da dispersão sobre a lógica da modalidade; das respostas institucionais em ternos de gestão metropolitana, nas mudanças que se operam nas formas resultantes desse processo de expansão ou nos impactos que tais modelos impõem sobre ambiente construído e natural.

\section{Método empregado}

Os resultados que estão sendo apresentados neste artigo abarcam 19 municípios da Região Metropolitana de Campinas ${ }^{1}$ e tiveram como principal base de dados as ementas estabelecidas para toda a sua legislação urbanística aprovada e instituída entre os anos de 1970 e 2006. 0 universo pesquisado abrangeu apenas leis e leis complementares, sem considerar decretos e outras normas hierarquicamente inferiores. ${ }^{2}$

0 método desenvolvido consistiu em pesquisar, nos sites das Câmaras e Prefeituras Municipais, essa legislação e classificá-la por tipos e por décadas (1970, 1980, 1990, 2000), em bancos de dados separados por município. Tal classificação considerou 0 conjunto de dispositivos legais urbanísticos tradicionalmente instituídos em seus grandes grupos: plano diretor, uso e ocupação do solo, parcelamento do solo e perímetro urbano, discriminando-se, entretanto, já nesse primeiro momento, leis referentes a condomínios horizontais e loteamentos fechados para efeitos de contabilização e análise especial e considerando a profusão desses tipos de assentamentos na Região. A classificação em cada um desses grandes grupos se deu a partir da leitura de todas as ementas das leis para a sua inclusão no grupo mais indicado e na década correspondente.

Para efeitos de precisão na contabilização das leis classificadas por grupo, as buscas foram feitas em dois momentos, o primeiro através de palavras-chave presentes nas ementas e o segundo, a partir da seleção destas por ano. A rigor, o segundo momento de busca funcionou como uma etapa de checagem da primeira, de forma a incluir dispositivos que não tinham sido, por algum motivo, encontrados no primeiro momento. As palavras-chave definidas para as buscas por grupo foram: 


\begin{tabular}{|c|c|c|}
\hline \multicolumn{2}{|c|}{ Grupo } & \multirow[t]{2}{*}{ Palavra-chave } \\
\hline Plano Diretor & $\longrightarrow$ & \\
\hline Perímetro urbano & $\longrightarrow$ & $\begin{array}{l}\text { Perímetro urbano } \\
\text { Expansão urbana }\end{array}$ \\
\hline Uso e ocupação do solo & $\longrightarrow$ & $\begin{array}{l}\text { Uso e ocupação do solo } \\
\text { Zoneamento } \\
\text { Zona } \\
\text { Código de Obras }\end{array}$ \\
\hline Parcelamento do solo & $\longrightarrow$ & $\begin{array}{l}\text { Parcelamento do solo } \\
\text { Loteamento } \\
\text { Desafetação } \\
\text { Uso comum do povo }\end{array}$ \\
\hline Loteamento fechado & $\longrightarrow$ & $\begin{array}{l}\text { Loteamento fechado } \\
\text { Condomínio }\end{array}$ \\
\hline
\end{tabular}

A checagem por ano, no momento posterior, possibilitou alargar a busca para leis urbanísticas de interesse, incluindo aquelas que não continham, a priori, as palavras-chave estipuladas. Nessa seleção, procurou-se encontrar todas as normas que, em menor ou maior grau, interferiram nos aspectos de regulação do uso, ocupação e parcelamento do solo, observando-os à luz das estratégias de planejamento e gestão estruturadas nos planos diretores e outros instrumentos de caráter planificador.

No momento seguinte, toda a legislação levantada foi sistematizada a partir da leitura de suas ementas, observando-se não só os aspectos quantitativos determinados pela recorrência no aparecimento de determinados tipos de leis, mas também os seus propósitos específicos identificados, sem ainda verificar e analisar os seus conteúdos, o que se pretende fazer em próxima etapa da pesquisa, exclusivamente para os dispositivos que tratam da questão da expansão urbana na Região. Nessa etapa, as leis foram classificadas por tipos no conjunto de cada grande grupo, permitindo observar os seus principais objetivos e alcances.

\section{Resultados preliminares: a teia legislativa e a regulação urbanística na Região Metropolitana de Campinas}

Foram contabilizadas 3.087 leis urbanísticas nos 19 municípios pesquisados pertencentes à Região Metropolitana de Campinas entre 1970 e 2006, cuja classificação, por grandes grupos e por ano, pode ser visualizada nas tabelas abaixo: 
Tabela 1 - Número de leis aprovadas nos municípios da Região Metropolitana de Campinas por grandes grupos entre 1970 e 2006

\begin{tabular}{|c|c|c|c|c|c|c|}
\hline Município & PD & LUOS & LPS & LPU & LLF & Total \\
\hline Americana & 4 & 28 & 187 & 7 & 1 & 227 \\
\hline Artur Nogueira & 10 & 43 & 23 & 14 & 1 & 91 \\
\hline Campinas & 4 & 82 & 483 & 18 & 6 & 593 \\
\hline Cosmópolis & 1 & 18 & 84 & 37 & 2 & 154 \\
\hline Eng. Coelho & 1 & 0 & 17 & 1 & 3 & 22 \\
\hline Holambra & 2 & 5 & 13 & 9 & 1 & 30 \\
\hline Hortolândia & 3 & 25 & 63 & 1 & 1 & 93 \\
\hline Indaiatuba & 4 & 94 & 140 & 7 & 3 & 248 \\
\hline Itatiba & 28 & 95 & 96 & 38 & 1 & 259 \\
\hline Jaguariúna & 13 & 17 & 38 & 21 & 6 & 95 \\
\hline Monte Mor & 2 & 5 & 65 & 31 & 0 & 106 \\
\hline Nova Odessa & 3 & 37 & 88 & 15 & 0 & 143 \\
\hline Paulínia & 6 & 52 & 105 & 5 & 5 & 173 \\
\hline Pedreira & 2 & 14 & 28 & 8 & 0 & 52 \\
\hline Santa Bárbara & 10 & 55 & 80 & 9 & 3 & 157 \\
\hline Sto. Antônio & 7 & 19 & 20 & 8 & 2 & 56 \\
\hline Sumaré & 4 & 26 & 165 & 12 & 4 & 211 \\
\hline Valinhos & 6 & 112 & 124 & 46 & 4 & 292 \\
\hline Vinhedo & 7 & 25 & 44 & 8 & 1 & 85 \\
\hline Total & 117 & 752 & 1.879 & 295 & 44 & 3.087 \\
\hline
\end{tabular}

Fonte: elaboração própria, a partir de dados levantados nas Câmaras Municipais.

Legenda: PD: Plano Diretor; LUOS: Lei de Uso e Ocupação do Solo; LPS: Lei de Parcelamento do Solo; LPU: Lei de Perímetro Urbano; LLF: Lei de loteamento fechado/condomínio. 


\section{Gráfico 1 - Participação dos grandes grupos de leis urbanísticas} no total de leis urbanísticas aprovadas nos municípios da Região Metropolitana de Campinas (1970-2006)

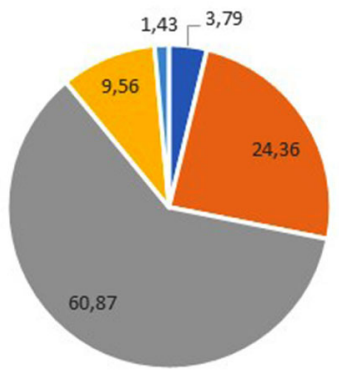

- Plano Diretor

" Lei de Uso e Ocupação do Solo

" Lei de Parcelamento do Solo

- Perímetro urbano

. Loteamento fechado

Fonte: elaboração própria, a partir de dados levantados nas Câmaras Municipais.

Tabela 2 - Número de leis urbanísticas aprovadas nos municípios da Região Metropolitana de Campinas por década (1970-2006)

\begin{tabular}{|c|c|c|c|c|c|}
\hline Município & 1970 & 1980 & 1990 & 2000 & Total \\
\hline Americana & 83 & 55 & 38 & 51 & 227 \\
\hline Artur Nogueira & 13 & 12 & 34 & 32 & 91 \\
\hline Campinas & 239 & 138 & 119 & 97 & 593 \\
\hline Cosmópolis & 70 & 41 & 25 & 18 & 154 \\
\hline Eng. Coelho & 0 & 0 & 13 & 9 & 22 \\
\hline Holambra & 0 & 0 & 13 & 17 & 30 \\
\hline Hortolândia & 0 & 0 & 45 & 48 & 93 \\
\hline Indaiatuba & 29 & 56 & 96 & 67 & 248 \\
\hline Itatiba & 35 & 105 & 55 & 64 & 259 \\
\hline Jaguariúna & 11 & 18 & 34 & 32 & 95 \\
\hline Monte Mor & 13 & 25 & 41 & 27 & 106 \\
\hline Nova Odessa & 42 & 41 & 24 & 36 & 143 \\
\hline Paulínia & 35 & 72 & 45 & 21 & 173 \\
\hline Pedreira & 11 & 17 & 15 & 9 & 52 \\
\hline Santa Bárbara & 36 & 41 & 29 & 51 & 157 \\
\hline Sto. Antônio & 9 & 11 & 21 & 15 & 56 \\
\hline Sumaré & 38 & 84 & 50 & 39 & 211 \\
\hline Valinhos & 93 & 39 & 95 & 65 & 292 \\
\hline Vinhedo & 21 & 17 & 33 & 14 & 85 \\
\hline Total & 778 & 772 & 825 & 712 & 3.087 \\
\hline
\end{tabular}

Fonte: elaboração própria a partir de dados levantados nas Câmaras Municipais.

Obs.: Municípios de Engenheiro Coelho, Holambra e Hortolândia foram desmembrados no ano de 1991, por essa razão não possuem leis contabilizadas nas décadas de 1970 e 1980. 
É possível observar, da interpretação dos dados apresentados, que há uma diferença significativa entre as quantidades apresentadas por grandes grupos de leis, mesmo se fosse considerado um outro arranjo nesse agrupamento, como, por exemplo, a inclusão do grupo de loteamentos fechados/condomínios no grupo de parcelamento do solo. Este é o que apresenta a maior quantidade em números absolutos de leis promulgadas no período, mais relacionadas ao processo de urbanização e de expansão urbana, seguido do grupo das leis de uso e ocupação do solo que se concentram mais nos aspectos relativos a utilização e ocupação de lotes já existentes, embora não exclusivamente a estes. Em termos relativos, o grande grupo de parcelamento do solo abrange mais de $60 \%$ de toda a legislação aprovada, muito acima do segundo grupo, relacionado a uso e ocupação do solo, que representa $24,36 \%$. As leis dos planos diretores não são menos significativas, em termos absolutos, considerando, via de regra, a complexidade das suas estruturas e a abrangência de seus conteúdos. Estas, entretanto, são superadas, em expressão, pelas leis de alteração de perímetro urbano, que também possuem fortes vínculos com as de parcelamento do solo, já que as aberturas de novos loteamentos urbanos dependem, em geral, de que as propriedades a serem parceladas estejam no interior desses perímetros. Em termos relativos, estas últimas possuem uma relevância no espectro da legislação urbanística aprovada.

Ao observar os números por município, nota-se uma discrepância das leis de parcelamento do solo em relação às demais nos municípios de Americana, Campinas, Paulínia e Sumaré. Em menor grau, destacam-se também os municípios de Indaiatuba e Valinhos, com uma distribuição mais equilibrada em relação às leis de uso e ocupação do solo. Nestes, há uma sensível consonância com as taxas de crescimento populacional e/ou do parque industrial na primeira década analisada. Outro aspecto que merece ser destacado é o número total relativamente pequeno (em relação aos números dos demais municípios) de leis de uso e ocupação do solo no município de Campinas. O levantamento mais minucioso da legislação urbanística produzida nesse município demonstrou, entretanto, que foram editados 129 decretos municipais de alteração de zoneamento, concentrados, principalmente entre as décadas de 1970 e 1980.

A quantidade de leis aprovadas por década apresentada, na segunda tabela, demonstra uma relativa constância quanto ao número total de promulgações em cada um dos períodos, ainda que a década de 1990 desponte com um número consideravelmente maior em relação às demais. A considerar, entretanto, que a década de 2000 figure de forma interrompida nesta pesquisa, já que está delimitada pelo ano de 2006, não é possível aferir se, de fato, a tendência é descendente, tendo sido a década de 1990, então, uma década atípica. Supõe-se, como hipótese de investigação, que, com a aprovação dos planos diretores, em sua maioria, na segunda metade dos anos 2000, tenha havido uma diminuição de leis aprovadas - questão que merecerá uma investigação futura. Além disso, deve-se considerar a criação de três municípios no início da década de 1990, fator indutor do aumento de leis, como é possível visualizar para o caso de Hortolândia. Em paralelo, a análise específica de cada município revela uma tendência diferente da geral, uma 
vez que para vários, como é o caso de Campinas, Cosmópolis, Itatiba, Nova Odessa, Paulínia, Pedreira, Santa Bárbara e Sumaré, houve uma diminuição do número total de leis entre as décadas de 1980 e 1990, ao contrário de outros, cujo crescimento foi expressivo, como em Hortolândia, Indaiatuba e Valinhos.

Analisando esses números à luz da configuração populacional dos municípios, é possível concluir que existe uma forte correlação entre número de leis promulgadas e os seus respectivos tamanhos populacionais, conforme demonstrado no gráfico e no índice de correlação abaixo $(0,87)$. Além disso, há uma fraca correlação entre número total de leis promulgadas por década e as taxas geométricas de crescimento populacional da Região, questão que deve ser relativizada em razão de dois fatores já mencionados: primeiro, considerando-se o alto número de decretos de alteração de zoneamento instituídos em Campinas (129 ao todo), concentrados, em sua maioria, entre as décadas de 1970 e 1980, que, se fossem contabilizados, acresceriam expressivamente os números dessas duas primeiras colunas; e, segundo, a criação de três municípios que acresceram 71 leis ao número total dos outros municípios na década de 1990. Se essas duas variáveis fossem consideradas no cômputo, concluir-se-ia que haveria uma correlação média entre esses dois fenômenos, conforme demonstrado abaixo.

Gráfico 2 - Número total de leis urbanísticas promulgadas entre 1970 e 2006 e tamanho populacional no ano de 2006 nos municípios da Região Metropolitana de Campinas (percentuais)

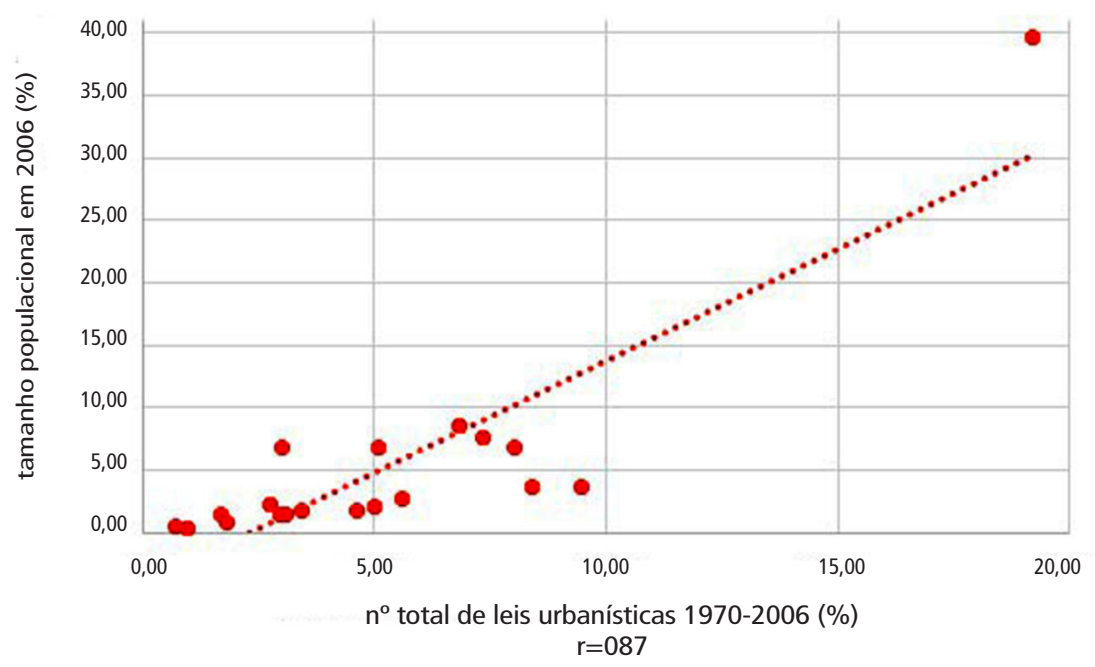

Fonte: elaboração própria, a partir de dados levantados nas Câmaras Municipais e Pesquisa Amostral do Censo do IBGE, de 2006. 
Gráfico 3 - Número total de leis urbanísticas promulgadas entre 1970 e 2006 e Taxa Geométrica de Crescimento Populacional da Região Metropolitana de Campinas entre 1970 e 2006

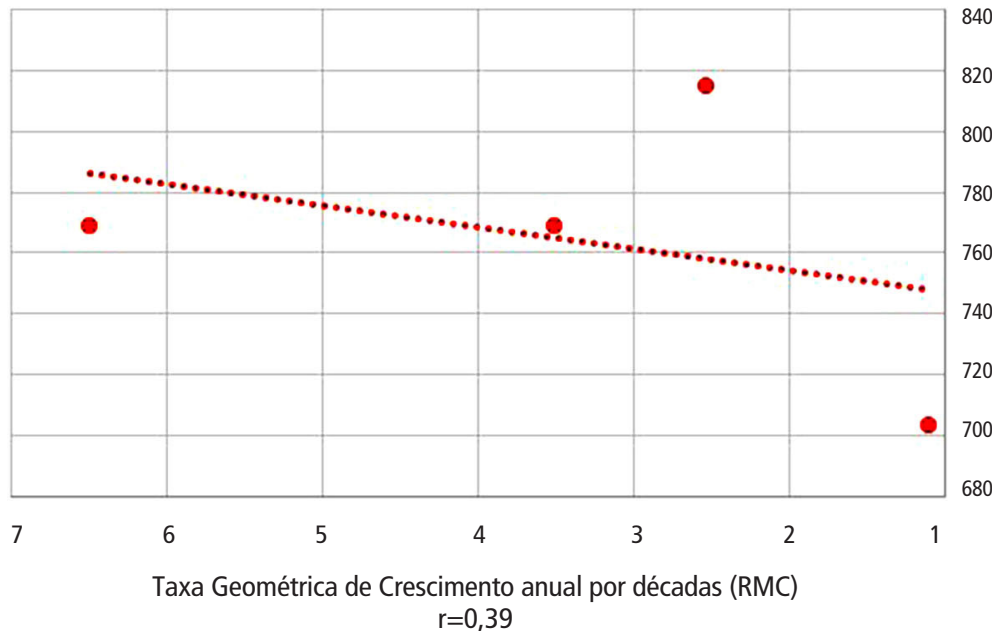

Fonte: elaboração própria, a partir de dados levantados nas Câmaras Municipais e Séries históricas de contagem populacional dos Censos do IBGE de 1970, 1980, 1991 e 2006.

Gráfico 4 - Número total de leis urbanísticas promulgadas entre 1970 e 2006* e Taxa Geométrica de Crescimento Populacional da Região Metropolitana de Campinas entre 1970 e 2006
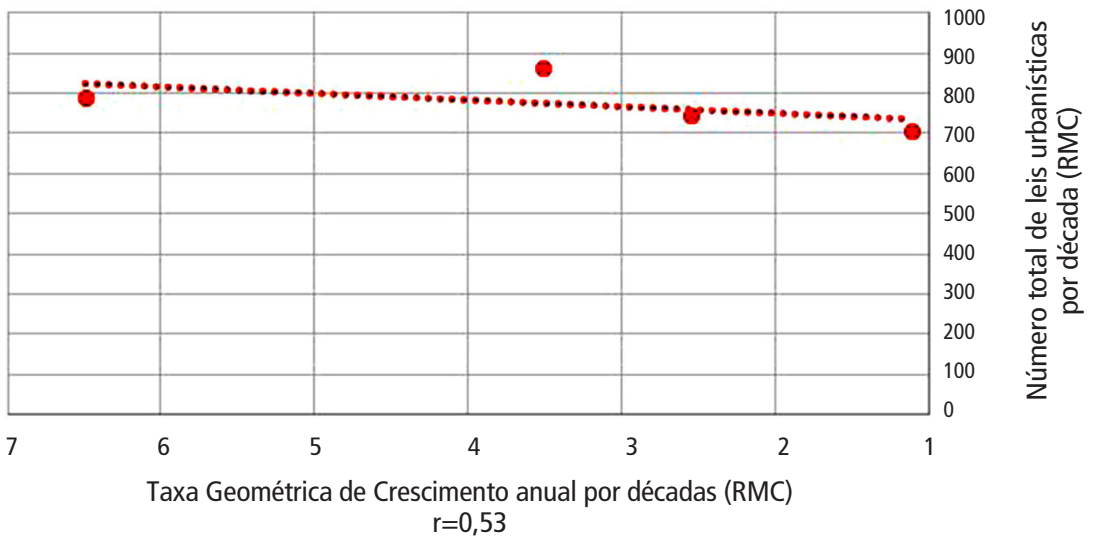

Fonte: elaboração própria, a partir de dados levantados nas Câmaras Municipais e Séries históricas de contagem populacional dos Censos do IBGE de 1970, 1980, 1991 e 2006.

*Com inclusão de 113 decretos de alteração de zoneamento de Campinas e exclusão de 71 leis promulgadas nos municípios de Engenheiro Coelho, Holambra e Hortolândia. 
Tabela 3 - Número total de leis promulgadas na Região Metropolitana de Campinas por grandes grupos e por década entre 1970 e 2006

\begin{tabular}{c|c|c|c|c|c|c}
\hline Ano & PD & LUOS & LPS & LPU & LLF & Total \\
\hline 1970 & 32 & 81 & 529 & 135 & 1 & 778 \\
1980 & 20 & 148 & 547 & 54 & 3 & 772 \\
1990 & 26 & 255 & 467 & 59 & 18 & 825 \\
2000 & 39 & 268 & 336 & 47 & 22 & 712 \\
\hline Total & 117 & 752 & 1.879 & 295 & 44 & 3.087 \\
\hline
\end{tabular}

Fonte: Elaboração própria, a partir de dados levantados nas Câmaras Municipais.

Legenda: PD: Plano Diretor; LUOS: Lei de Uso e Ocupação do Solo; LPS: Lei de Parcelamento do Solo; LPU: Lei de Perímetro Urbano; LLF: Lei de loteamento fechado/condomínio.

Outro aspecto que deve ser levado em conta é o grupo no qual o conjunto de leis está inserido, já que há uma inversão de sentidos nos acréscimos em determinados grupos por décadas. Ao observar a Tabela 3, percebe-se que, enquanto houve uma diminuição crescente do número de leis criadas entre 1970 e 2006 de parcelamento do solo e alteração dos perímetros urbanos, também houve um crescimento do número de leis criadas para uso e ocupação do solo e loteamentos fechados/condomínios.

Parece natural que, em um processo desacelerado de crescimento populacional numa região cujo corolário é a expansão horizontal espraiada, as normas relativas à abertura de novos loteamentos deixem de aumentar, sendo complementadas por outras, mais características das formas de urbanização contemporâneas, representadas pelas leis de loteamentos fechados/condomínios, cujo número de instrumentos se expandiu sobremaneira na década de 2000, na pretensão de regulamentar os inúmeros casos que a Região abriga. Assim também pode-se dizer das normas mais relacionadas ao uso e ocupação dos lotes sob os auspícios de um desenvolvimento imobiliário que se intensifica nas últimas décadas, demandando instrumentos específicos nem sempre tratados ou estabelecidos nos planos diretores.

Ao se avaliar as quantidades de leis que estabelecem normas gerais nos planos diretores, uso e ocupação do solo e parcelamento do solo, conforme demonstrado na Tabela 4, depreende-se que, de fato, a legislação de uso e ocupação do solo ganha uma dimensão mais aguda nos anos 1990, assim como ocorre com os planos diretores na década de 2000, estes elaborados por força da lei federal 10.257/2001. Na década de 1990 ainda, não é desprezível o número de leis gerais que estabelecem normas de parcelamento do solo, mas em menor número das que se referem ao seu uso e ocupação. Raras são as leis que estabelecem conjuntamente as regras de parcelamento e de uso e ocupação do solo e, mais raras ainda, as que possuem todo o conjunto de normas em um único instrumento, como é o caso do Plano Diretor. No âmbito das normas gerais, as leis que estabelecem os planos diretores ganham em números absolutos 
(43), seguidas da quantidade de leis de uso e ocupação do solo (40) e de parcelamento do solo (39).

Verifica-se, entretanto, que as normas gerais estabelecidas são apenas uma parte da realidade do espectro de leis urbanísticas estabelecidas pelos municípios da Região. Não obstante à importância delas como instrumentos de controle e da gestão do espaço urbano, elas compõem uma parcela pequena dos mecanismos utilizados para que estes se efetivem. Se a estrutura legal que se estabelece com a implementação dessas normas não é simples, a composição de um conjunto amplo de dispositivos torna-as mais complexas e difíceis de serem operadas, só autorizadas para quem, de fato, esteja encerrado na burocracia administrativa do Poder Público municipal. Assim é que, ao observar as ementas de cada uma dessas leis aprovadas, observa-se uma outra lógica e que explica, de certa forma, a quantidade extensiva de tantos diplomas legais. 0 Gráfico 5 representa os números absolutos de leis urbanísticas, agora em subclassificações, considerando suas ementas.

Tabela 4 - Normas urbanísticas gerais aprovadas por município e por década

\begin{tabular}{|c|c|c|c|c|c|c|c|c|c|c|c|c|c|c|c|c|}
\hline & \multicolumn{6}{|c|}{ Plano Diretor } & \multicolumn{5}{|c|}{ LUOS } & \multicolumn{5}{|c|}{ LPS } \\
\hline & $\begin{array}{c}< \\
1970\end{array}$ & 1970 & 1980 & 1990 & 2000 & $\begin{array}{c}2006 \\
<\end{array}$ & $\begin{array}{c}< \\
1970\end{array}$ & 1970 & 1980 & 1990 & 2000 & $\begin{array}{c}< \\
1970\end{array}$ & 1970 & 1980 & 1990 & 2000 \\
\hline Americana & & $x$ & & $x$ & & $x$ & $x$ & & & $x$ & & & $x$ & $x$ & $\mathrm{x}$ & \\
\hline A. Nogueira & & $x$ & & & & $x$ & & & & & $x$ & & & & $x$ & \\
\hline Campinas & & $x$ & & $x$ & $x$ & & $x$ & & $x$ & $x$ & $x$ & $x$ & & & $x$ & $x$ \\
\hline Cosmópolis & & & & & & $x$ & & & & $x$ & $x$ & & & $x$ & $x$ & \\
\hline Eng. Coelho & & & & & $\mathrm{x}$ & & & & & & & & & & & \\
\hline Holambra & & & & & & $x$ & & & & & $x$ & & & & & $x$ \\
\hline Hortolândia & & & & $\mathrm{X}$ & & $x$ & & & & $x$ & & & & & $x$ & \\
\hline Indaiatuba & $x$ & & & & $x$ & & & & & & $x$ & & & $x$ & $x$ & \\
\hline Itatiba & & $x$ & & & $x$ & & & & & $x$ & $x$ & & & & $x$ & $x$ \\
\hline Jaguariúna & & & $x$ & & $x$ & & & & & & & & & & & $x$ \\
\hline Monte Mor & & & & $\mathrm{x}$ & & $x$ & & & & & & & & & & $x$ \\
\hline N. Odessa & & $x$ & & & $x$ & & & $x$ & & & & & $x$ & & & \\
\hline Paulinia & & $x$ & & $x$ & $x$ & & & $x$ & $x$ & $x$ & $x$ & & $x$ & & $\mathrm{x}$ & \\
\hline Pedreira & & & & & $x$ & & & & $x$ & & & & & $x$ & & \\
\hline Santa Bárbara & & $x$ & & & $x$ & & & & $x$ & $x$ & & & $x$ & & & \\
\hline S. Antônio & & & & $x$ & $x$ & & & & & & & & $x$ & & & \\
\hline Sumaré & & $x$ & & $x$ & $x$ & & & & & $x$ & & & $x$ & $x$ & & \\
\hline Valinhos & & $x$ & & $x$ & $x$ & & & $x$ & & $x$ & & & $x$ & & $x$ & \\
\hline Vinhedo & & & $x$ & & & $x$ & & $x$ & & & & & $x$ & & & \\
\hline Total & 1 & 10 & 2 & 9 & 14 & 7 & 2 & 5 & 5 & 19 & 9 & 1 & 13 & 7 & 13 & 5 \\
\hline
\end{tabular}

Fonte: elaboração própria, a partir de dados levantados nas Câmaras Municipais. 
Gráfico 5 - Quantidades percentuais de leis urbanísticas aprovadas nos municípios da Região Metropolitana de Campinas subclassificadas a partir de suas ementas (1970 - 2006)

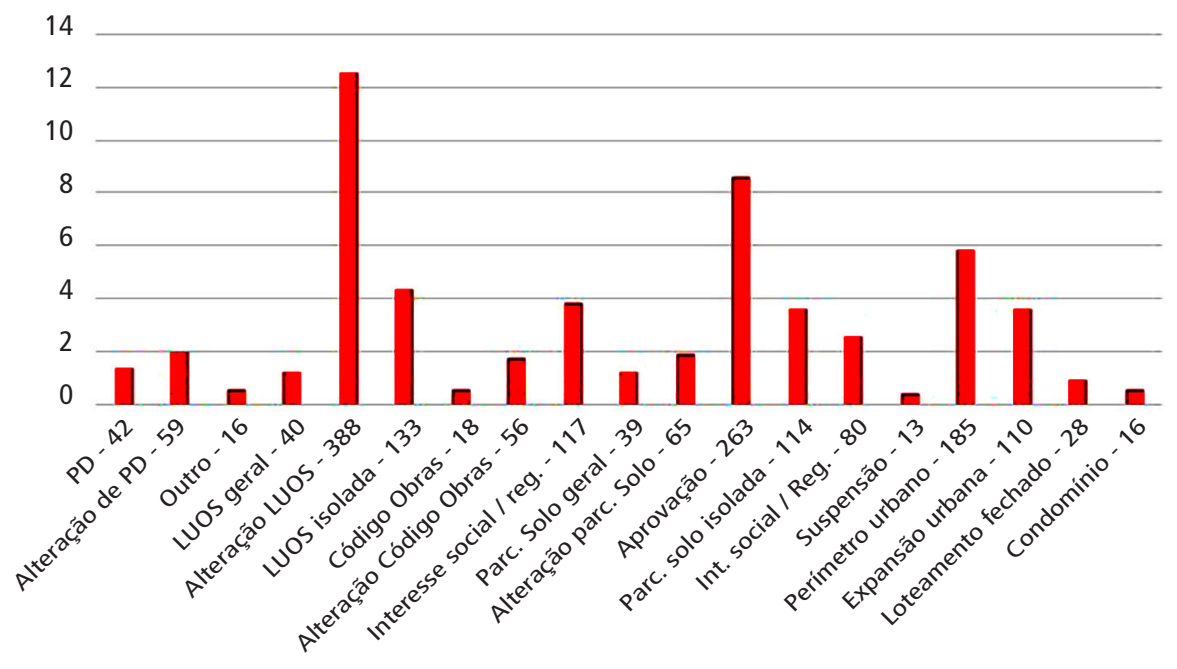

Fonte: elaboração própria, a partir de dados levantados nas Câmaras Municipais.

Gráfico 6 - Participação das leis referentes à desafetação de áreas públicas no conjunto de toda a legislação urbanística aprovada na Região Metropolitana de Campinas (1970-2006)

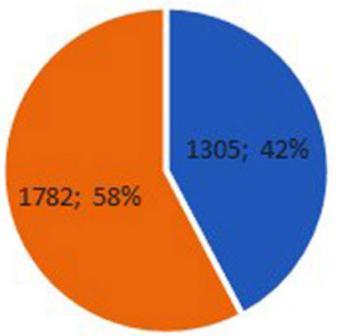

- Desafetação

" Outras leis

Fonte: Elaboração própria a partir de dados levantados nas Câmaras Municipais. 
A considerar a grande quantidade de leis referentes à desafetação dos espaços públicos de uso comum do povo, optou-se por excluir essa quantidade desse gráfico e incluí-la no Gráfico 6, que apresenta a sua quantidade tendo em vista todo o conjunto das demais leis. Os Gráficos de 7 a 11 representam essas subclassificações por grandes grupos, trazendo os números absolutos e os percentuais da participação de cada tipo no conjunto do grupo a que pertence.

Gráficos 7, 8, 9, 10 e 11 - Tipos de leis urbanísticas por grandes grupos, aprovadas nos municípios da Região Metropolitana de Campinas (1970-2006)

\section{Plano Diretor}

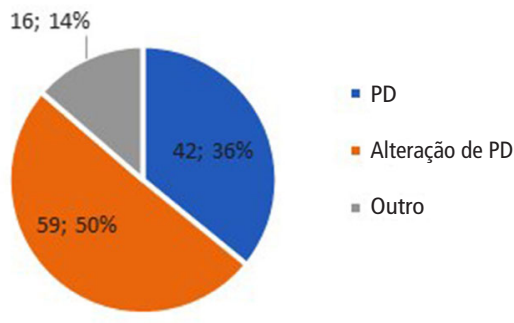

Parcelamento do solo

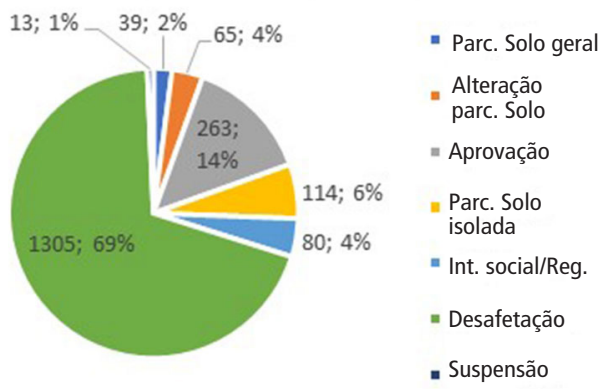

Uso e ocupação do solo

- LUOS geral

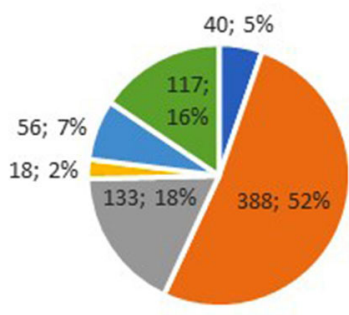

" Alteração LUOS

" LUOS isolada

= Código Obras

- Alteração Código Obras

- Interesse social / reg.

\section{Perímetro urbano}

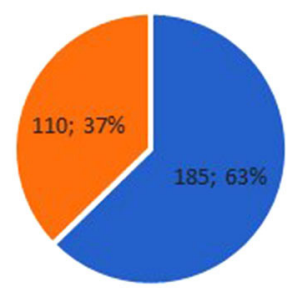

- Perímetro urbano

- Expansão urbana

\section{Fechamentos}

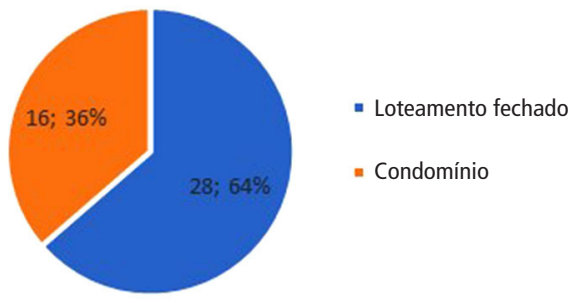


Cabe notar, nesses gráficos, uma certa diversidade de tipos observados, incluindo nesses grupos, os casos de normas específicas de interesse social ou de regularização fundiária/edilícia e os Códigos de Obras e Edificações que, em alguns municípios, figuram como os principais instrumentos de controle, inclusive de uso, ocupação e parcelamento do solo. No caso das leis de perímetros urbanos e de fechamentos, foi possível distinguir as variações de termos e que, em última instância, poderiam potencializar problemas conceituais e de natureza jurídica a serem posteriormente investigados.

Em outro campo de análise, entretanto, demonstra-se que, em significativa minoria, as leis principais de planos diretores, uso e ocupação do solo e parcelamento do solo, que deveriam se constituir como plenas na aplicação das regras de controle e gestão do uso, ocupação e parcelamento do solo, sucumbem-se a um vasto aparato de outros mecanismos legais, mais numerosos, operando modificações muitas vezes substanciosas sobre elas, como pode ser notado para cada grande grupo de leis. Ao lado de 43 planos diretores elaborados entre 1970 e meados de 2006, foram aprovadas 59 leis de modificação desses instrumentos, sem contar possíveis modificações posteriores a 2006, que não foram contabilizadas. No caso do grupo das de uso e ocupação do solo, apenas $7 \%$ delas figuram como leis gerais ou principais, ao lado de $52 \%$ que foram instituídas para promover-lhes alterações pontuais - como, por exemplo, modificações nos perímetros de zonas - na sua composição original. Soma-se a estas, um conjunto não menos significativo (18\%) de leis isoladas que não possuem um caráter de alteração da lei maior, mas que definem regras de uso e ocupação do solo independentemente desta.

Para o grupo de parcelamento do solo, embora a quantidade de leis modificativas não seja tão expressiva como é no caso das de uso e ocupação do solo, observa-se uma quantidade não pequena de leis isoladas e de leis específicas que promoveram e autorizaram a aprovação de determinados loteamentos ou desmembramentos, denunciando uma aparente discricionariedade dos poderes envolvidos que, independentemente dos ritos estabelecidos em lei maior (como aqueles estabelecidos pela lei federal 6766/1979, por exemplo), aprovaram, sob força legal, empreendimentos com todas as suas excepcionalidades, em fuga às normas principais.

Sob a mesma ótica, estão os casos das leis que promoveram as desafetações dos espaços públicos de uso comum do povo, cuja quantidade abarca quase a maioria absoluta de todas as leis promulgadas nas quatro décadas analisadas, perfazendo um total de 1.305 leis. Esse aspecto mereceu uma atenção especial, não só pela quantidade expressiva em que apareceram nos momentos de busca, em geral em todos os municípios da Região, mas também pelo propósito contido em suas disposições. Essa classificação, estabelecida pelo Código Civil de 1916, instituiu uma diferença substancial entre os vários tipos de áreas públicas constituídas, seja através de sua origem, seja através das operações de doação ou aquisição. Nesse âmbito, convencionou-se uma separação entre aqueles bens imobiliários públicos entendidos como sendo de uso comum do povo, cujo domínio está na esfera da comunidade e cuja utilização pode se dar livremente, sem depender de prévia autorização 
do Poder Público, tais como mares, rio, ruas e praças; entre os chamados bens especiais, destinados ao cumprimento das funções públicas, tendo sua utilização restrita à população em geral (por exemplo, repartições públicas e edifícios públicos); e entre os bens chamados dominicais ou dominiais, que incluem as áreas patrimoniais, disponíveis, inclusive, para serem alienadas pelo poder público detentor de seu domínio. Nessa classificação, entende-se, no campo do Direito, que a finalidade para as quais esses bens foram incorporados e suas características determinam a sua chamada afetação e, portanto, a mudança dessa finalidade só poderia ocorrer após um processo de desafetação, ou seja, alteração de sua natureza ou finalidade, através da instituição de uma lei específica. Não foi possível saber ainda, pelo alcance da pesquisa até agora, quais foram os objetivos que motivaram tantos processos de desincorporação do uso comum do povo. É certo, porém, que, nessas transposições, o caráter público das áreas e sua utilização irrestrita pela população da Região foram sumariamente ceifados em detrimento de finalidades possivelmente privatistas.

\section{Discussão: regulação urbanística às avessas?}

A quantidade de leis urbanísticas aprovadas no período demonstra, a princípio, uma intensa atividade de gestão do uso, ocupação e parcelamento do solo, que se faz de forma associada entre os poderes Executivo e Legislativo. ${ }^{3}$ Trata-se de um modelo de gestão no qual, incrementalmente, são definidos instrumentos legais, ora para estabelecer normas de caráter abrangente, coadunadas com o processo de planificação técnica adotada, muitas vezes, pela via do plano diretor; ora para acomodar e legalizar situações anômalas ou estranhas a essas normas gerais estabelecidas.

Verifica-se, nesse sentido, que as práticas cotidianas da gestão do uso, ocupação e parcelamento do solo são mais complexas e operam em realidades mais abrangentes do que aquelas previstas nas normas principais. A compreensão dessa lei legislativa sobre a qual é operada a máquina da gestão pública depende eminentemente da compreensão desse cotidiano que se faz sob motivações bastante variadas, para além das iniciativas técnicas mais identificadas com os quadros funcionais públicos que manejam esses instrumentos.

Ao observar a forte correlação entre quantidades de dispositivos legais de caráter urbanístico e os tamanhos populacionais das municipalidades, pode-se supor que a prática legislativa esteja associada ao conjunto de demandas da população residente, sob os mais variados aspectos. Ainda que, mesmo para tal suposição, seja necessário realizar outras investigações, pode-se corroborar a ideia de que, no âmago dos processos de planejamento urbano no Brasil e de sua interface com a regulação do uso e ocupação do solo, encontra-se uma veia privatista e de proteção à propriedade privada, utilizando-se de forma cabalmente institucionalizada, os poderes existentes para efetivar 0 pleno aproveitamento da propriedade em utilizações que, nem sempre, voltam-se ao interesse coletivo e público.

$\mathrm{Na}$ investigação sobre o desenvolvimento das estratégias de gestão e regulação do uso e ocupação do solo no município 
de São Paulo entre 1947 e 1972, Feldman (2005, p. 111) demonstrou os três aspectos que se inovariam, ainda nos anos 1940, com a instituição de um modelo de zoneamento sob a base do Comprehensive Planning norte-americano. Primeiro, sua aplicação como ordenador do solo para o conjunto da cidade; segundo, tendo diferentes regras que se aplicam a diferentes partes da cidade; e, terceiro, uma postura que explicita objetivos relacionados com os valores imobiliários, orientador dos investimentos econômicos sobre a terra urbana.

0 modelo desse zoneamento orientado para manejar as diferentes partes e suas características peculiares utiliza-se, ideologicamente, dos argumentos na defesa dos aspectos específicos no mosaico dos tecidos urbanos diferenciados, com capacidades diversas de infraestrutura existente e condicionantes heterogêneas, justificadas, ainda, pela funcionalização dos espaços na relação com uma organização territorial coerente com essas premissas. Os fundamentos desse modelo orientaram as concepções dos instrumentos legais nas cidades brasileiras sob uma prática corrosiva da lógica funcionalista em detrimento da lógica mercantilista na utilização da terra como ativo financeiro. 0 princípio da função social da propriedade, nesse aspecto, que sempre esteve na base da retórica constitucional no Brasil, mistifica-se a partir dos inúmeros planos diretores e de leis de zoneamento formulados para atender a tais princípios, vinculando-se, entretanto, na sua concepção original, aos moldes privatistas e coadunados com os processos especulativos da terra. A engrenagem institucional que se pauta por quantidades abusivas de alterações dessas leis não é, portanto, estranha à essência que se estrutura nessas práticas, sendo parte do processo de produção do espaço urbano.

No caso da Região Metropolitana de Campinas, as evidências demonstram um exacerbado processo de institucionalização dos mecanismos de adaptação, flexibilização e acomodação das regras principais para atender a uma dinâmica que não cabia estar fixada nessas normas de caráter mais abrangente.

$\mathrm{Na}$ classificação realizada a partir das ementas legais, foi possível perceber que, em alguns municípios, tão logo o instrumento geral era promulgado, uma avalanche de leis posteriores ia inserindo modificações e alterações sequencialmente. A julgar pelos possíveis equívocos cometidos na concepção desses textos legais, pode-se entrever duas hipóteses: a primeira de que, por serem muito detalhados, acabavam por falhar em algum aspecto, devendo receber um substitutivo para a disposição equivocadamente instituída. A segunda de que, ao contrário, por serem muito abertos e gerais, deixavam de abarcar todas as situações não previstas, devendo, portanto, preencher a lacuna legislativa deixada para não corroborar atos discricionários. Desconfia-se, entretanto, que tantos instrumentos legais contenham tamanhos vícios de origem, recorrentemente e sistematicamente cometidos por quatro décadas.

0 caminho que esta pesquisa procura mostrar é que estas serviram como a base de fundo, o alicerce principal, de profunda relevância, sobre as quais operavam as modificações necessárias ao funcionamento dos processos imobiliários. Assim é que uma quantidade de 122 instrumentos urbanísticos gerais e de caráter abrangente, incluindo planos diretores, leis de uso, ocupação e parcelamento 
do solo instituídos em quatro décadas nos 19 municípios da Região demonstra a relevância destes e de sua natureza, intrínseca às práticas de gestão.

Os números apresentados na Tabela 4 podem ajudar a revelar alguns significados e oferecer mais chaves para a compreensão da "subserviência" desses institutos às condutas político-administrativas na gestão do uso do solo. Se é fácil antever, por exemplo, o porquê dos planos diretores aprovados estarem concentrados na década de 1970 e 1980, indaga-se por que se intensificou o processo de aprovação de leis de uso e ocupação do solo e parcelamento do solo na década de 1990, e, mais especificamente, no ano de 1996?

Além disso, cabe salientar que essas normas se combinam a outro conjunto de leis isoladas ou contendo regras excepcionais, como é o caso daquelas voltadas ao interesse social ou à regularização edilícia/fundiária que também é estabelecida a partir da infração às regras convencionais, exigindo procedimentos voltados à anistia ou à facilitação de parâmetros, permitindo o enquadramento das situações existentes nos atos de licenciamento. No caso das leis classificadas no grupo de uso e ocupação do solo, estas leis específicas (de modificação ou isoladas) somam 694, do total de 752 leis levantadas, o que corresponde a $92 \%$ delas. No caso das leis de parcelamento do solo, do total de 1.879 leis contabilizadas, 1.840 compõem-se de casos excepcionais, incluindo as de desafetação, conforme já mencionado, correspondendo a $97 \%$ de toda a legislação desse campo. Nesse sentido é que se pergunta onde está a regulação, se suas regras constituintes são pensadas e aplicadas a partir, principalmente, das excepcionalidades?
Nessa via da excepcionalidade que caracteriza a regulação urbanística da Região, há todo um conjunto de normas estabelecidas nos seus municípios que parece concorrer com dispositivos gerais consagrados, como é o caso da lei federal 6766/1979, que contém disposições sobre o parcelamento do solo urbano. Uma leitura atenta dessa lei demonstra uma clara intenção coletivista em alguns aspectos estabelecidos, como é o caso da preocupação com a destinação de áreas públicas, seja para promover a circulação viária, seja para criar espaços de importância para a vida comunitária. As ações que motivam quaisquer impactos nessas destinações ou causam obstruções nos acessos a esses espaços parecem colidir com 0 seu "espírito". Mas não é somente sob as circunstâncias que induzem a criação de normas específicas para promover adaptações às realidades contemporâneas que o fenômeno deve ser olhado, senão a partir das concepções que traduzem as referências que melhor expressam os anseios vinculados a essa produção (Sposito e Goes, 2014). Trata-se, portanto, de uma cultura do morar que perpassa as várias parcelas da sociedade e que passa a ser referendada pelos mecanismos estatais.

Quase todos os municípios, com exceção de Pedreira, Nova Odessa e Monte Mor, possuem pelo menos uma lei que regulamenta os condomínios horizontais ou os loteamentos fechados (ou o fechamento daqueles abertos) na Região de Campinas. É possível afirmar, entretanto, que todos os municípios possuam qualquer tipo de regra referente a esses tipos de assentamentos, já que, mesmo não possuindo leis específicas, incluem disposições nas suas leis de parcelamento do solo, como já foi possível investigar para os casos excepcionados acima. 
A quantidade desses tipos de leis, como foi possível notar na Tabela 3, aumentou consideravelmente nas décadas de 1990 e 2000 . Mesmo com as explícitas intenções municipalistas da Constituição de 1988 e as mudanças que a própria lei 6766 já sofreu nesse contexto, com a promulgação da lei federal 9785/1999, a colisão com alguns de seus princípios fundantes evidencia o colapso da sua estrutura diante da realidade figurada em instrumentos legais que, embora procurem contornar tais regras essenciais, confrontam-nas sem parcimônia.

A tentativa, no âmbito nacional, de regulamentar esses expedientes que passaram a ser adotados irrestritamente por muitas municipalidades brasileiras, com a proposição do PL 20/2007 que compunha um conjunto de normas, inclusive voltadas para esses casos, ficou emperrada na Câmara Federal, já que não se coadunava com os reais interesses dos empreendedores imobiliários. Nessa lacuna, restou, aos municípios, instituir suas próprias normas, suas próprias regras, sem se importar com princípios estruturantes ou fundamentos que deveriam nortear, com base nas prescrições de caráter federal, a produção do solo urbano.

A quantidade significativa de leis que promoveram a desincorporação dos espaços púbicos de uso comum do povo, transformando-os em bens patrimoniais, passíveis de serem alienados, é outro aspecto que merece ser destacado. 0 montante de 1.305 leis, que representam $42 \%$ de todas as leis urbanísticas levantadas, revela uma outra face relativa a concepção e tratamento das áreas públicas existentes. Nesse caso, a concorrência não se deu no nível federal, mas no estadual, já que a Constituição Estadual de 1989 estabelecia, no inciso VII do artigo 180, que as áreas definidas em projeto de loteamento como áreas verdes ou institucionais não poderiam, em qualquer hipótese, ter sua destinação, fim e objetivos originariamente estabelecidos alterados.

A pesquisa demonstrou que os municípios já praticavam os atos de desafetação desde o período inicial da pesquisa, mas continuaram a fazê-lo mesmo após a promulgação dessa lei estadual. Em 2007, foi proposta uma emenda constitucional que abriu exceção a tal regra para casos de loteamentos cujas áreas verdes ou institucionais estivessem total ou parcialmente ocupadas por núcleos habitacionais de interesse social destinados à população de baixa renda e cuja situação estivesse consolidada ou de difícil reversão. Em 2008, uma nova emenda abriu tal exceção também a imóveis ocupados por organizações religiosas para as suas atividades finalísticas.

Não houve, pelo menos a partir da contabilização dessas leis promulgadas, qualquer alteração nas quantidades anteriores ou posteriores a esses dispositivos constitucionais estabelecidos. Resta saber, entretanto, se as finalidades impostas para tais alterações justificam a sua abundância. Se foram destinados para a implantação de equipamentos estatais ou como reserva fundiária em programas habitacionais ou se foram transferidos a organizações comunitárias, clubes recreativos ou instituições religiosas, como foi possível depreender da leitura de algumas ementas, a questão não parece estar na refuncionalização em si, mas na atitude dos poderes Executivo e Legislativo em reposicionar o domínio de terras originalmente destinadas para serem espaços livres de uso comunitário de caráter amplo, autônomo e independente para o domínio das negociações político-administrativas, utilizando-as, muitas 
vezes, para finalidades alheias às da própria comunidade que detinha o seu domínio. Supõe-se, além disso, que tais desafetações se associaram aos processos de fechamento dos loteamentos e condomínios, numa forma de regularizar a questão dos acessos a essas áreas, restringindo-os, por força da transposição dominial, apenas aos moradores locais.

\section{Conclusão}

A questão da regulação do uso e ocupação do solo na produção do espaço urbano ganha novos contornos no mundo contemporâneo, na medida em que expõe os novos arranjos institucionais estabelecidos para os desafios competitivos da economia global, indicando um novo papel e uma nova postura do Estado nas suas práticas tradicionais de controle e disciplinamento dessa produção.

A mudança do "administrativismo" para o "empreendedorismo", conforme apontou Harvey (2005), corrobora a ideia de que a atuação do Estado passa a ser postulada, contraditoriamente, pelos objetivos do mercado, estabelecendo novos horizontes de planejamento e gestão que se conformam a partir de alianças e acordos em uma governança urbana que se traduz nas chamadas parcerias público-privadas. Tal postura admite abrandamento e flexibilização dos tradicionais instrumentos de controle de que o Estado lança mão para efetivar os objetivos preconizados nos processos de planejamento territorial nas suas diversas escalas.

Nos novos tempos potencializados pelo enfraquecimento do Estado com os atuais arranjos produtivos do capitalismo tardio, mudam as interfaces, mas a lógica presente nas estruturas de regulação parece não mudar. Ao contrário, parece se consolidar com a criação de novos instrumentos e mecanismos (como é o caso das Operações Urbanas, por exemplo) vinculados ao novo pensamento empreendedorista. De qualquer forma, essas associações não precisam estar necessariamente presentes em grandes projetos ou em grandes escalas de intervenção, mas se mostram presentes nos cotidianos da gestão pública, que se apresenta complexa e, ao mesmo tempo, embaraçada em uma teia legislativa que é difícil de compreender e dominar.

\section{Sidney Piochi Bernardini}

Universidade Estadual de Campinas, Faculdade de Engenharia Civil, Arquitetura e Urbanismo, Departamento de Arquitetura e Construção. Campinas, SP/Brasil.

sidpiochi@fec.unicamp.br 


\section{Notas}

Isabela Cristina Guerreiro, aluna de graduação do Curso de Arquitetura e Urbanismo da Faculdade de Engenharia Civil, Arquitetura e Urbanismo e bolsista de Iniciação Científica, colaborou com a elaboração do texto.

(1) Atualmente, a Região Metropolitana de Campinas agrega 20 municípios após ter sido incluído o município de Morungaba por força da lei estadual complementar 1.234/2014. Entretanto, como a pesquisa tem como horizonte de término de tempo o ano de 2006, optou-se por não incluí-lo.

(2) Exceção feita ao caso de Campinas, já que uma suspeita em relação ao pequeno número de leis promulgadas de uso e ocupação do solo induziu um levantamento dos decretos relativos às mudanças de uso e ocupação do solo nos anos 1970 e 1980.

(3) Cabe notar que a análise não distinguiu as leis que foram revogadas ou que ainda estejam em vigor. No caso das leis principais, por exemplo, embora sem revogação expressa, a promulgação de uma nova revoga, em geral, a anterior. A pesquisa procurou contabilizar toda a quantidade de leis promulgadas, com o objetivo de verificar como se dá a dinâmica da regulação e em que medida as modificações e alterações conformam o conjunto total de dispositivos levantados.

\section{Referências}

ALVES, M. A. da S. (2007). Espacialidades escala e complexidade dos problemas metropolitanos: o caso da Região Metropolitana de Campinas. Tese de Doutorado. Campinas, Universidade Estadual de Campinas.

ANTHONY, J. (2004). Do state growth management regulations reduce sprawl? Urban Affairs Review, v. 39, n. 3, pp. 376-397.

BAENINGER, R. e GONÇALVES, R. D. P. (2000). Novas Espacialidades no Processo de Urbanização: A Região Metropolitana de Campinas. In: XII ENCONTRO NACIONAL DE ESTUDOS POPULACIONAIS. Anais. Caxambu, n. p.

BENGSTON, D. N.; FLETCHER, J. O. e NELSON, K. C. (2004). Public policies for managing urban growth and protecting open space: policy instruments and lessons learned in the United States. Landscape and Urban Planning, v. 69, n. 2, pp. 271-286.

BOARNET, M. G.; MCLAUGHLIN, R. B. e CARRUTHERS, J. I. (2011). Does state growth management change the pattern of urban growth? Evidence from Florida. Regional Science and Urban Economics, v. 41, n. 3, pp. 236-252.

BONDUKI, N. e SANTORO, P. F. (2009). O desafio do parcelamento do solo a partir do periurbano: a composição do preço da terra na mudança de uso do solo rural para urbano. In XIII ENCONTRO DA ANPUR. Anais. Florianópolis, n. p.

BUZBEE, W. W. (2003). Urban form, health, and the law's limits. American Journal Of Public Health, v. 93, n. 9 , pp. $1395-1399$ 
CAIADO, M. C. S. e PIRES, M. C. S. (2006a). “Campinas Metropolitana: transformações na estrutura urbana atual e desafios futuros". In: CUNHA, J. M. P. da et al. Novas Metrópoles Paulistas: população, vulnerabilidade e segregação. Campinas, Nepo/Unicamp, pp. 275-304.

(2006b). O verso e o reverso da dinâmica metropolitana: mobilidade populacional e estruturação socioespacial. In: XV ENCONTRO NACIONAL DE ESTUDOS POPULACIONAIS. Anais, Caxambu, n. p.

(2007). “Expansão recente na Região Metropolitana de Campinas: dispersão e novas formas urbanas". In: REIS, N. G. e TANAKA, M. S. (coords.). Brasil-estudos sobre dispersão urbana. São Paulo, FAU-USP, pp. 81-112.

CANO, W. e BRANDÃO, C. A. (2002). A Região Metropolitana de Campinas - urbanização, economia, finanças e meio ambiente. Campinas, Unicamp.

COSTA, A. K. S. (2012). Loteamentos fechados e serviços ambientais. Tese de doutorado. Campinas, Universidade Estadual de Campinas.

CUNHA, J. M. P. (2006). Novas metrópoles paulistas: população, vulnerabilidade, segregação. Campinas, Nepo/Unicamp.

FELDMAN, S. (2005). Planejamento e zoneamento: São Paulo, 1947-1972. São Paulo, Edusp.

FONSECA, R. B.; DAVANZO, A. M. Q. e NEGREIROS, R. M. (2002). Livro Verde: desafios para a gestão da Região Metropolitana de Campinas. Campinas, Unicamp.

FREITAS, E. L. H. de (2008). Loteamentos fechados. Tese de doutorado. São Paulo, Universidade de São Paulo.

HARRIS, K. E. (2015). Because we can doesn't mean we should and if we do: urban communities, social and economic justice, and local economic-development-driven eminent domain practices. Economic Development Quarterly, v. 29, n. 3, pp. 245-261.

HARVEY, D. (2005). A produção capitalista do espaço. São Paulo, Annablume.

HILLS JR, R. M., e SCHLEICHER, D. (2015). Planning an Affordable City. lowa L. Rev., v. 101, n. 91, pp. 91-136.

JARDIM, M. R. (2007). Gestão do espaço regional: cooperação e conflito nas relações intergovernamentais. Os casos da Região Metropolitana de Campinas e do Consórcio do Grande ABC. Dissertação de Mestrado. São Paulo, Universidade de São Paulo.

MIRANDA, Z. A. I. (2002). A incorporação de áreas rurais às cidades: um estudo de caso sobre Campinas, São Paulo. Tese de doutorado. Campinas, Universidade Estadual de Campinas.

MITICA NETO, H. (2008). Urbanização em Campinas: mudanças no tecido urbano no entorno da Rodovia D. Pedro I. Tese de Doutorado. São Paulo, Universidade de São Paulo.

PEREIRA, R. H. de M. (2008). Processos socioespaciais, reestruturação urbana e deslocamentos pendulares na Região Metropolitana de Campinas. Dissertação de Mestrado. Campinas, Universidade Estadual de Campinas.

PIRES, A. (2004). Da rocinha aos enclaves: figurações do rural em Vinhedo. Tese de Doutorado. Campinas, Universidade Estadual de Campinas.

PIRES, M. C. S. (2007). Morar na metrópole - expansão urbana e mercado imobiliário na Região Metropolitana de Campinas. Tese de doutorado. Campinas, Universidade Estadual de Campinas.

REIS, N. G. (2006). Notas sobre urbanização dispersa e novas formas de tecido urbano. São Paulo, Via das Artes. 
RESNIK, D. B. (2010). Urban sprawl, smart growth, and deliberative democracy. American Journal of Public Health, v. 100, n. 10, pp. 1852-1856.

SAIZEN, I.; MIZUNO, K. e KOBAYASHI, S. (2006). Effects of land-use master plans in the metropolitan fringe of Japan.Landscape and Urban Planning, v. 78, n. 4, pp. 411-421.

SILVA, M. F. P. de S. e (2009). A expansão dos condomínios fechados no Brasil e no mundo: redimensionando o fenômeno. In: XIII ENCONTRO DA ANPUR. Anais. Florianópolis, n. p.

SOJA, E. (2000). Postmetropolis: critical studies of cities and regions. Oxford, Blackwell.

SPOSITO, M. E. e GOES, E. M. B. (2014). Espaços fechados e cidades. Insegurança urbana e fragmentação socioespacial. São Paulo, Unesp.

VILLAÇA, F. (1998). O espaço intraurbano no Brasil. São Paulo, Nobel/Fapesp/Lincoln Institute. (2012). Reflexões sobre as cidades brasileiras. São Paulo, Studio Nobel.

XI, F. et al. (2012). The potential impacts of sprawl on farmland in Northeast China Evaluating a new strategy for rural development.Landscape and Urban Planning, v. 104, n. 1, pp. 34-46.

Texto recebido em 7/abr/2016

Texto aprovado em 2/jun/2016 